Proceedings

\title{
Using the Artificial Intelligence for Ecosystem Services (ARIES) model to explore the value of socio-economic ecosystems using the Jinshan Qingshui Wetland in Northern Taiwan as a case study
}

\author{
Shu-Hui Hung ${ }^{1,}{ }^{*}$, Ju- Hui Hsu ${ }^{2}$ \\ Affiliation 1; shuhui@mail.ntpu.edu.tw \\ 2 Affiliation 2; wra10021@gmail.com \\ * Correspondence : Institute of Natural Resource Management, National Taipei University. \\ 151, University Rd., San Shia Dist., New Taipei City 237, Taiwan. shuhui@mail.ntpu.edu.tw; Tel: +886 \\ 926376322
}

\begin{abstract}
Due to human over-exploitation, global wetland areas have been degraded and are disappearing due to human over-exploitation. The service value of wetland ecosystems has no market and is frequently ignored. Jinshan Qing Shui Wetland is in the north corner of Taiwan. It is a private inland wetland that is at risk of flooding. With the Jinshan Qingshui Wetland as a case study, the ARIES model was used as a research tool to select 4 types of currently well-established ecosystem service projects: "sediment regulation, soil carbon storage, net value of pollination, and net value of outdoor recreation." The results estimate that the annual value of "sediment regulation" is about US $\$ 26,915$; the annual value of "soil carbon storage" is about US $\$ 1,246,370$; the annual value of "net value of pollination" is about US\$182,100; and the annual value of "net value of outdoor recreation" can reach US\$1,199,253. The estimated value of the four items is about US $\$ 2.65$ million. In addition, focus interviews with water conservancy experts, chiefs, and NGO groups were conducted; the Likert scale was used to analyze the views of different stakeholders on wetlands. Through evaluating the social, economic, and environmental value of wetlands, and through integrating the opinions of all stakeholders, this research provides the government with reference points to an overarching management plan of wetlands, with potential ecosystem service value.
\end{abstract}

Keywords: ecosystem services; wetland; ARIES model; Likert scale

Citation: Hung, S.; Hsu, J., 2022, Using the Artificial Intelligence for Ecosystem Services to explore the value of socio-economic ecosystems using the Jinshan Qingshui Wetland in Northern Taiwan as a case study. SUPTM 2022 conference proceedings sciforum-054294.

https://doi.org/10.31428/10317/10469

Publisher's Note: UPCT and Sciforum stays neutral with regard to jurisdictional claims in published maps and institutional affiliations.

Copyright: (C) 2022 by the authors. Submitted for possible open access publication under the terms and conditions of the Creative Commons Attribution (CC BY) license (https://creativecommons.org/license s/by/4.0/).

\section{Introduction}

Wetlands provide "ecosystem services" for humans. Humans rely on the functions of ecosystems to sustain life. Wetland ecosystems aid in flood prevention and regulation of industrial and domestic wastewater. Wetlands can also absorb carbon dioxide, thereby helping combat climate change. The rapid development of research surrounding wetland ecosystems will increase the value of these "services" provided by such ecosystems [1]. If one can understand the service functions of the natural system and accurately estimate the benefits of ecosystem services to support better natural re-source management, one can generate a win-win situation for ecosystem protection and economic development [2, 3].

The Millennium Ecosystem Assessment pointed out that human activities have significantly reduced the earth's environmental resilience and bio-capacity, while the impact of the loss of natural resources on the economy has been underestimated [4]. The evaluation of ecosystem service value is a cross-disciplinary work. It is necessary to understand the various services provided by the ecosystem, human well-being, and the social and economic benefits obtained from it. If the value of various ecosystem services is added up, the total value of an ecosystem can be estimated. However, the actual quantification of various ecosystem services requires a huge amount of parameter data, which consumes manpower, material resources and time and is, therefore, not easy to achieve.

This study uses the ARIES model as a research tool, analyzes the benefits of ecosystem services based on the patterns and data produced by the model, integrates the opinions of various stakeholders, and ultimately provides the government with appropriate
26 


\section{Area of study}

management recommendations on wetlands, so that wetlands can provide better sustaina- 1 bility and ecological services.

This study uses the Jinshan Qingshui Wetland in Taiwan as the research area (Figure 1). The Jinshan Qingshui Wetland is located at the northern tip of Taiwan. It is a common alluvial plain of Sulfur Creek, Xishi Creek and Qingshui Creek. It is the first stop in Taiwan for winter migratory birds traveling, as well as last supply station for birds traveling north on the return leg. Literature points out that world-class endangered birds have been found here. Currently, some parts of the wetland are mainly used for agriculture, but there are large areas of wetlands that are fallow or abandoned.

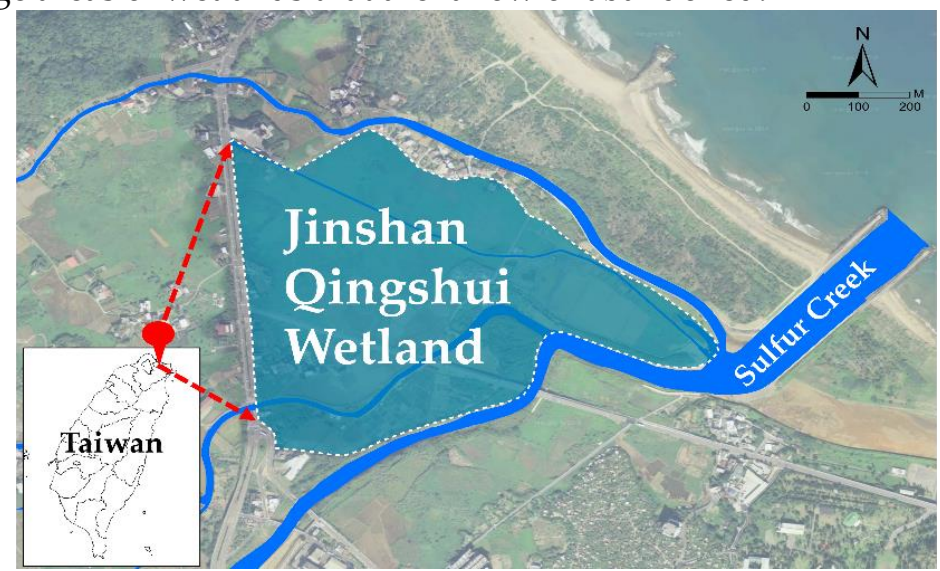

Figure1. Map of the study site: the Jinshan Qingshui Wetland.

\section{Methodology}

\subsection{ARIES Model}

ARIES (ARtificial Intelligence for Ecosystem Services) is an ecosystem service function evaluation model developed by the United Nations Department of Economic and Social Affairs (UNDESA), the United Nations Environment Programme (UNEP) and the Basque Center for Climate Change (BC3). The evaluation functions include sediment retention, carbon storage, pollination and outdoor recreation.

\subsection{Likert scale}

The Likert scale was established by Dr. Rensis Likert in 1932 to formulate a measurement method for questionnaires. The purpose is to measure the research subject's subjective or objective judgment of a description, the subject's degree of agreement or disagreement with the description, and to research subject's attitude or opinion of a certain topic. The researcher converts the answer of each statement into a number of components and calculates it in a cumulative or average manner to obtain the attitude score of this group of respondents [5].

\section{Results}

\subsection{ARIES model evaluation results}

Figures 2 and 3 show that potential soil removed mass and soil retained mass caused by vegetation is estimated to contribute 1017.54 tons and 737.79 tons of soil erosion caused by rainfall and land runoff, respectively, for a total of 1755.33 metric tons/year. Based on the market price of US\$15.33 per metric ton, the estimated service value is $15.33^{*} 1755.33=\mathrm{US} \$ 26,915 /$ year. SoilGrids is a system for digital soil mapping based on global compilation of soil profile data. The ARIES model of soil carbon storage uses SoilGrids as modeling data. Figure 4 shows that the soil carbon storage quality (soil carbon storage) is $31,159.25$ tons/year; calculated with a carbon price of 40 US dollars per ton, the value of soil carbon storage is $40^{*} 31,159.25=1,246,370$ US dollars. According to the correlation of crop pollination supply (supply) and insect pollination to obtain the best crop yield (demand), the pollination surplus/deficit can be calculated in the regional pollination supply and demand in the grid cell (Figure 5). The average annual crop output value and net value of pollination (net value of pollination) is US\$182,099.72. Outdoor recreation supply is seen as a multiplicative function of naturalness and the distance-driven accessibility of nature-based factors of attractiveness. Outdoor recreation demand is an additive function of population density, and distance to main cities combined with travel time (net value of outdoor recreation). The surplus and deficit are $47 \%$ 
and 53\% respectively (Figure 6). The average number of tourists in the Jinshan area in the past three years 1 is about 840,000 . Assuming per capita consumption as US $\$ 10$ and profit as $20 \%$, one can see that the annual 2 tourism benefit provided by the wetland ecosystem is valued at US\$1,199,252.91.

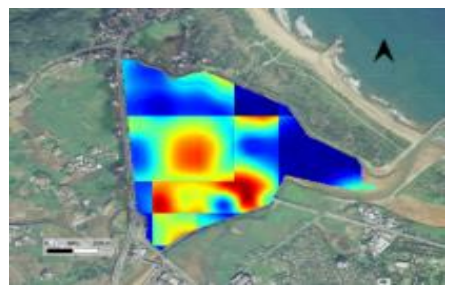

(a)

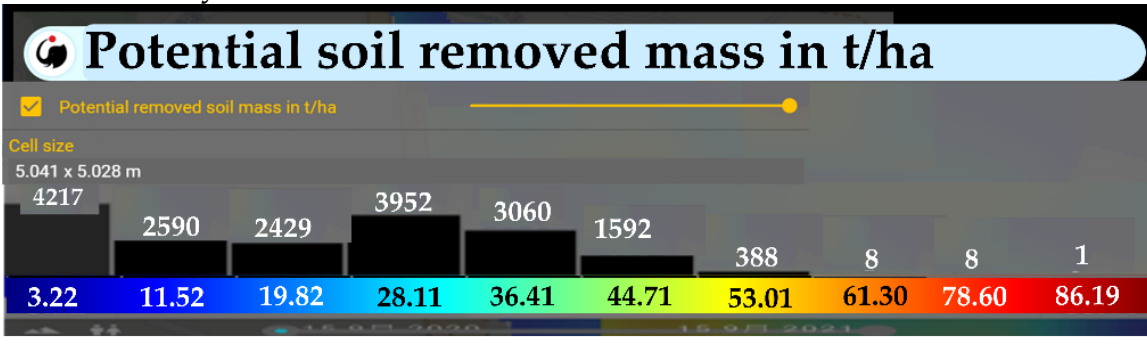

(b)

Figure2. (a) The ARIES model of potential soil removed mass model at the Jinshan Qingshui Wetland; (b) The bar chart of potential soil removed mass model at the Jinshan Qingshui Wetland.

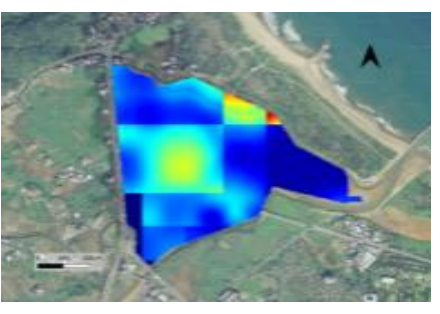

(a)

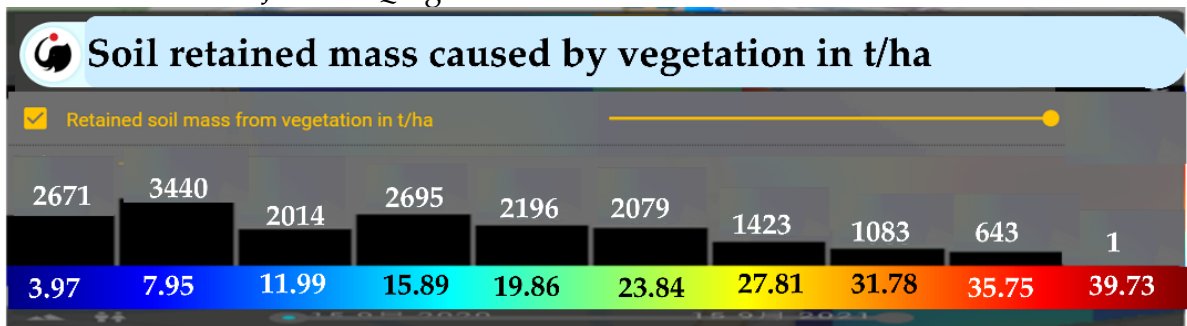

(b)

Figure3. (a) The ARIES model of soil retained mass caused by vegetation at the Jinshan Qingshui Wetland; (b) The bar chart of soil retained mass caused by vegetation at the Jinshan Qingshui Wetland.

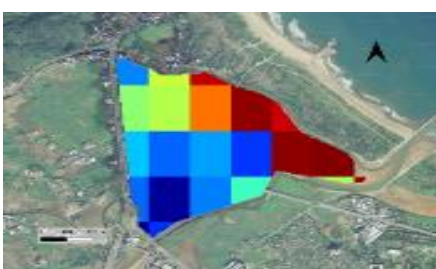

(a)

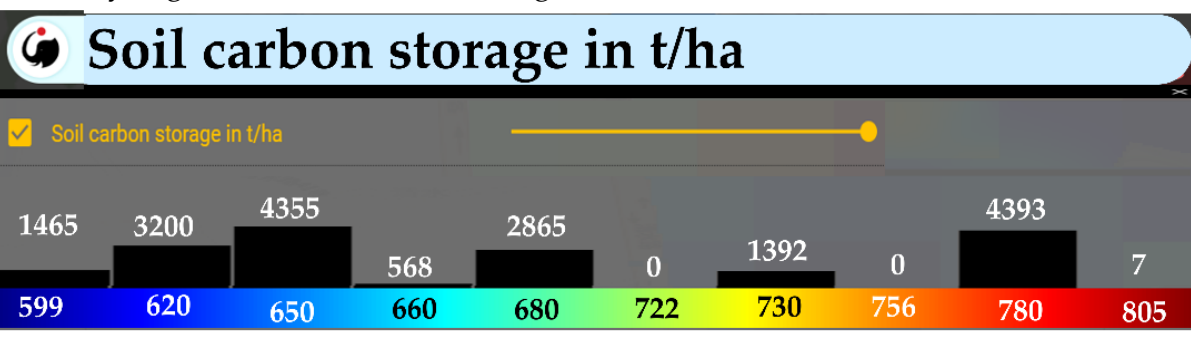

(b)

Figure4. (a)The ARIES model of soil carbon storage at the Jinshan Qingshui Wetland; (b) The bar chart of soil carbon 8 storage at the Jinshan Qingshui Wetland.

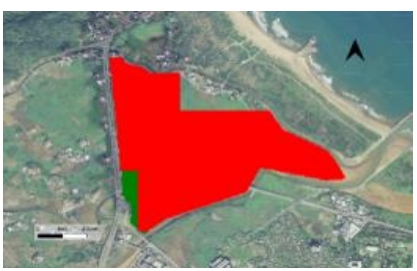

(a)

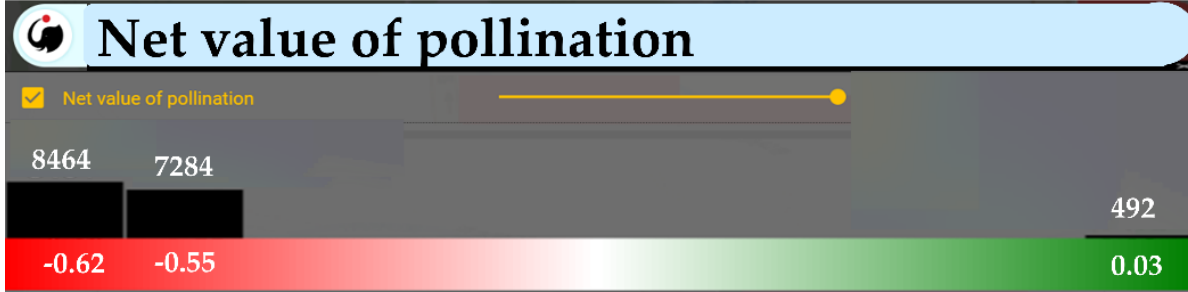

(b)

Figure5. (a) The ARIES model of net value of pollination at the Jinshan Qingshui Wetland; (b) The bar chart of 10 net value of pollination at the Jinshan Qingshui Wetland.

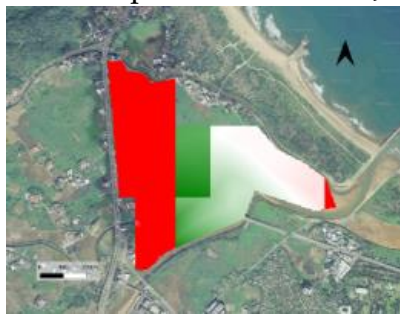

(a)

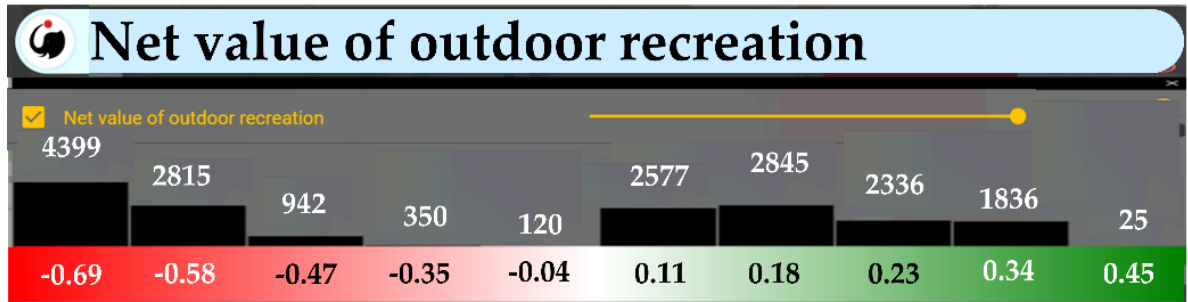

(b)

Figure6. (a) The ARIES model of net value of outdoor recreation at the Jinshan Qingshui Wetland; (b) The bar chart of 12 net value of outdoor recreation at the Jinshan Qingshui Wetland. 


\subsection{Stakeholder questionnaire survey}

This research focuses on the three ethnic groups of Jinshan area chiefs and people, water conservation experts, and NGO groups. It uses a questionnaire survey and uses the Likert scale as a measurement scale to study the priority of stakeholders for ecosystem services. (Priorities) and the degree of perception (Figure $7)$.

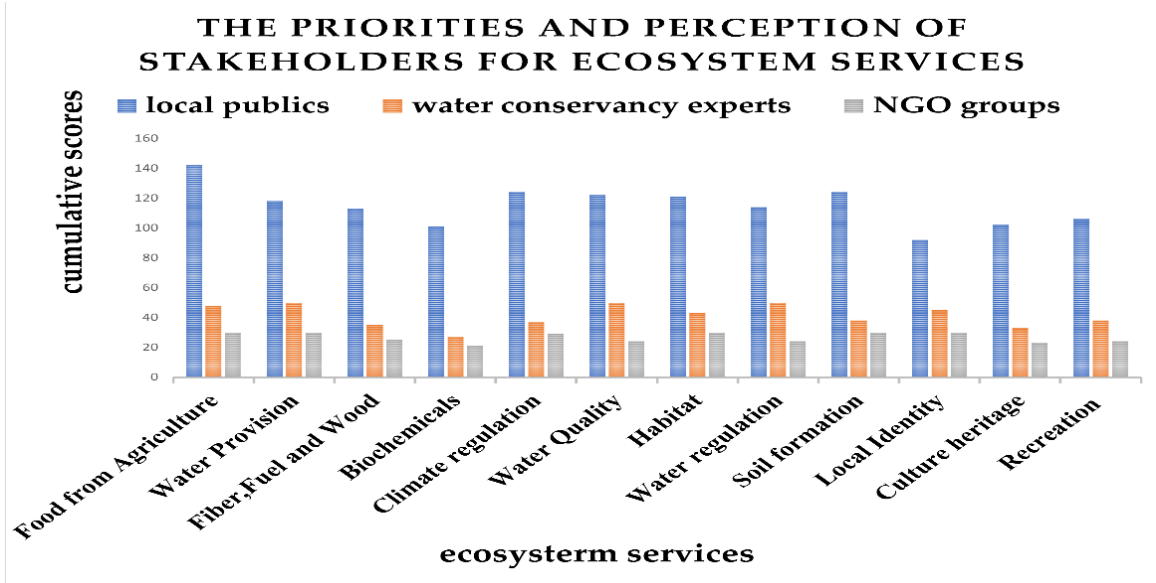

Figure7. The priorities and perception of ecosystem services as cumulative scores of local publics, water conservancy experts and NGO groups

\section{Conclusion}

According to the results of the study, the annual benefit of the ecosystem services of Jinshan Qingshui Wetland is approximately US $\$ 2.65$ million. Local residents pay more attention to food supply and crop growth ecosystem services, and water conservancy experts prioritize ecosystem services related to water resources. NGO groups attach importance to being more evenly oriented and balanced. The results of the study also found that the perception of ecosystem services is related to occupations and not directly related to gender, education level and age. In terms of the relevance of wetlands to the environment, economy, and society, all three ethnic groups agree that wetlands can provide ecosystem services such as purifying water quality, cooling temperatures, improving air quality, increasing income, and promoting health. Jinshan Qingshui Wetland is located in the lower reaches of the Sulfur Creek. In the upper reaches of the Sulfur Creek, there is the Yangmingshan National Park with rich forest resources. In the middle reach there is the Bayan settlement famous for its water terraces. The outlet of Sulfur Creek has a unique fishery culture that burns sulphur stones to fish. This research suggests that the government should integrate the natural resources from upstream to downstream in the Suanxi River Basin by means of river basin management, proper development of forestry, agriculture, fisheries, and tourism, as well as integration of the wetland ecosystem with the economy, in order to maximize the value of sustainable wetland ecosystem services.

\section{References}

1. Aryal, K., B.R. Ojha, and T. Maraseni, Perceived importance and economic valuation of ecosystem services in Ghodaghodi wetland of Nepal. Land Use Policy, 2021. 106: p. 105450.

2. Fischer, A. and A. Eastwood, Coproduction of ecosystem services as human-nature interactions-An analytical framework. Land Use Policy, 2016. 52: p. 41-50.

3. Yuan, M.-H. and S.-L. Lo, Ecosystem services and sustainable development: Perspectives from the food-energy-water Nexus. Ecosystem Services, 2020. 46: p. 101217.

4. Panel, M.E.A., Ecosystems AND HUMAN WELL-BEING. 2005.

5. Harpe, S.E., How to analyze Likert and other rating scale data. Currents in Pharmacy Teaching and Learning, 2015. 7(6): p. 836850. 